\title{
SENTIDO GESTUAL DA FALA E O INGRESSO NO CAMPO DA LINGUAGEM EM MERLEAU-PONTY
}

\author{
Gestural sense of speech and entry into the field of language in Merleau-Ponty
}

Sentido de la palabra y lo ingreso en el campo de la lengua en Merleau-Ponty

Gilberto Hoffmann Marcon ReinALDO FurLAN

\begin{abstract}
Resumo: Como parte de um estudo mais amplo a respeito do desenvolvimento da temática da linguagem ao longo do projeto filosófico de Merleau-Ponty, propomos um recorte que aborde uma inflexão central do percurso, o sentido gestual da fala conforme apresentado em "Fenomenologia da Percepção", sob a perspectiva particular do ingresso no campo dos significantes linguísticos, visando compreender melhor a passagem da gestualidade geral para a fala propriamente dita. A conceptualização do sentido gestual da fala pretende auxiliar na superação de um modelo objetivista de linguagem, através da proposição de uma indissociabilidade entre significado e significante. Desvelar a forma através da qual o sistema de significantes estrutura-se como modalidade de abertura e de relação com o mundo constitui grande parte do desafio para que tal ultrapassagem se dê de forma efetiva. A aquisição da linguagem, por sua vez, apresenta um período desenvolvimental privilegiado para se refletir a respeito das particularidades do fenômeno expressivo, já que representa o momento na história individual em que o gesto dirige-se a um campo comum de ação e significação. Procuramos então abordar, sob esta perspectiva, a forma como o sentido gestual é capaz de significar e instituir um campo comum de ação e significação.
\end{abstract}

Palavras-chave: Merleau-Ponty; Linguagem; Gesto; Fenomenologia; Mundo comum.

\begin{abstract}
As part of a larger study on the development of the language theme throughout Merleau-Ponty's philosophical project, we propose na approach that addresses a central inflection of this course, the gestural sense of speech as presented in "Phenomenology of Perception", under the particular perspective of the entry into the field of linguistic signifiers, in order to better understand the passage from general gesturality to speech itself. The conceptualization of the gestural sense of the speech aims to help in overcoming an objectivist model of language, through the proposition of an inseparability between signified and signifier. To unveil the way in which the system of signifiers structures itself as a modality of openness and relationship with the world constitutes a major part of the challenge for such an overcoming to take place effectively. The acquisition of language, in turn, presents a privileged developmental period to reflect on the particularities of the expressive phenomenon, since it represents the moment in the individual history wherein the gesture is directed to a common field of action and signification. In this perspective, we try to approach the way in which the gestural sense is capable of signifying and instituting a common field of action and signification.
\end{abstract}

Keywords: Merleau-Ponty; Language; Gesture; Phenomenology; Common World.

Resumen: Como parte de un estudio más amplio sobre el desarrollo del tema de la lengua a lo largo del proyecto filosófico de Merleau-Ponty, proponemos un enfoque que aborda una inflexión central de este curso, el sentido gestual de la palabra tal como se presenta en "Fenomenología de la Percepción", perspectiva de la entrada en el campo de los significantes lingüísticos, para comprender mejor el pasaje de la gestualidad general a la propia palabra. La conceptualización del sentido gestual de la palabra pretende ayudar a superar un modelo objetivista del lenguaje, a través de la proposición de una inseparabilidad entre significados y significantes. Desvelar la forma en que el sistema de significantes se estructura como modalidad de apertura y relación con el mundo constituye una parte importante del desafío para que tal superación tenga lugar efectivamente. La adquisición del lenguaje, a su vez, presenta un período de desarrollo privilegiado para reflexionar sobre las particularidades del fenómeno expresivo, ya que representa el momento en la historia individual en el cual el gesto se dirige a un campo común de acción y significación. En esta perspectiva, tratamos de abordar la forma en que el sentido gestual es capaz de significar e instituir un campo común de acción y significación.

Palabras clave: Merleau-Ponty; Lenguaje; Gesto; Fenomenología; Mundo Común.

\section{Introdução}

A Psicologia encontra-se, hoje, em meio a um panorama epistemológico complexo. Observa-se uma grande diversidade de propostas teóricas e leituras possíveis de seu objeto de estudo, dado que por si só nos dá indício de que há uma dificuldade presente em se abordar a subjetividade de forma unificada, ou ainda, de compreender o fenômeno subjetivo em sua totalidade. Os limites do pensamento moderno, com os quais as ciências humanas procuraram lidar durante toda sua existência, fazem-se mais claros do que nunca ao psicólogo que se depara com uma subjetividade constituída no contexto cultural que podemos chamar de pós-modernidade no qual, muitas vezes, o sujeito aparece ora destituído da esponta- 
neidade característica da concepção de sua formação na idade moderna, ora sobrecarregado dela e, assim, desconectado de seu contexto social.

A questão da linguagem ou da produção de sentidos, seja no âmbito social, seja no âmbito da experiência individual, constitui-se como central na compreensão de uma subjetividade em sua totalidade relacional, isto é, inexoravelmente articulada em uma cultura. Afinal, é sempre alguém - uma singularidade - que fala ou se expressa, mas ao mesmo tempo essa expressão se dá necessariamente em uma determinada língua, que é pública. A questão da linguagem representa, desta forma, um objeto de estudo privilegiado para a compreensão dos processos socioculturais de subjetivação.

Neste sentido, acreditamos que o pensamento do filósofo francês Maurice Merleau-Ponty (19081961) apresenta interesse renovado ao pesquisador que se volta à compreensão da subjetividade contemporânea. Isto se deve ao fato de que a motivação central da reflexão merleau-pontiana - a necessidade de superação do modelo dualista cartesiano é de fato uma questão condizente com as limitações do contexto epistemológico atual (Furlan, 2012). Além disso, a reflexão do autor encontra-se posicionada de maneira privilegiada no diálogo com o discurso científico, dada a proximidade que Merleau-Ponty manteve com o mesmo, o que de fato constituiu um elemento metodológico central para o desenvolvimento de seu projeto filosófico (Veríssimo \& Furlan, 2006;2007).

A linguagem constitui um campo fenomênico de especial interesse no sentido de se compreender, no projeto merleau-pontiano, o âmbito da subjetividade em sua complexidade vivida. Trata-se de um ponto em que se articulam a particularidade da existência individual e um contexto cultural sedimentado que, se não determina o sujeito, oferece modos específicos através dos quais este poderá significar a própria experiência. $\mathrm{O}$ esforço merleau-pontiano, opondo-se às correntes do empirismo científico e do intelectualismo filosófico, complementares em sua adoção de um entendimento dualista de realidade, busca redescobrir a facticidade do sentido para além desta cisão: reinscrever, no âmbito do sensível, o inteligível. Para tanto, o autor pretende recorrer ao originário comum dos polos historicamente constituídos enquanto subjetivo e objetivo, consciência e natureza.

Trata-se de situar-se aquém desta tematização, anteriormente à reflexão racionalista que levou ao objetivismo e, desta forma, reconhecer que tal originário não é da ordem do pensado ou do tematizado, mas da ordem do vivido. Neste sentido, o tema da linguagem ocupa um lugar central no próprio desenvolvimento interno do projeto filosófico do autor, representando um campo de questões que se revela significativo no delineamento das possibilidades mesmas de uma redução fenomenológica que cumpra este papel reabilitador (Ferraz, 2009; Moutinho, 2006). Compreender melhor a relação entre o mundo sensível de núcleos significativos que polarizam a atividade do organismo e o corpo próprio como o meio expressivo primordial torna-se necessário na medida em que uma fenomenologia da linguagem deverá, para o autor, fundar-se sobre tal potência expressiva. Abordaremos alguns pontos que consideramos de especial interesse a respeito do sentido gestual da fala e sua relação com o ingresso da criança no mundo da linguagem, tendo em vista esclarecer de que forma eles embasam uma inserção da linguagem no campo do Sentir ${ }^{1}$.

\section{Significado, significante e sentido gestual}

O capítulo de "Fenomenologia da Percepção" dedicado à fala representa um momento privilegiado no qual o filósofo se volta à questão da linguagem de maneira direta. Tendo apresentado a noção de corpo próprio, estruturando uma subjetividade que se identifica à sua dimensão de abertura perceptiva ao mundo, o autor dirige-se então para a potência falante desse mesmo corpo, ou seja, sua capacidade de articular e produzir sentidos linguísticos, a qual surge como parte dessa potência total ${ }^{2}$ de ação em continuidade com um posicionamento existencial mais geral. Prenuncia-se aqui uma fundação da linguagem na fala, e da fala na potência gestual mais geral do corpo próprio.

O mote da reflexão de Merleau-Ponty (1945/2006b) nesse ponto é a recusa de uma diferenciação comum nas filosofias intelectualistas e efetuada de maneira marcada pelo empirismo científico: aquela entre pensamento e linguagem. Tal diferenciação tem por efeito opor os fenômenos da fala e do pensamento, ou seja, o ato expressivo encontra-se apartado da atividade subjetiva de constituição ou compreensão de sentidos, o que faz com que seu sentido original seja de fato perdido por completo. Com o objetivismo, seja através da via intelectualista seja através da via empirista, o que se perde de vista na tentativa de compreensão do fenômeno linguístico é o próprio sujeito da expressão, tomando-se como objeto de análise um significante supostamente vazio de expressividade, sempre contemplado na neutralidade de um vislumbre em terceira pessoa ${ }^{3}$.

Remontando a um tratamento objetivista da expressividade, tal equívoco encontra-se presente tanto nas concepções intelectualistas quanto empiristas do fenômeno linguístico. Neste ponto, assim

\footnotetext{
1 O que visamos com o termo é ao mesmo tempo o campo primordial e a estrutura fundamental da relação intencional entre os polos da consciência e do mundo. Sensibilidade e sensível são, assim, aspectos co-originários de toda a experiência: "O sentir é esta comunicação vital com o mundo que o torna presente para nós como lugar familiar de nossa vida. E a ele que o objeto percebido e o sujeito que percebe devem sua espessura. Ele é o tecido intencional que o esforço de conhecimento procurará decompor.' (Merleau-Ponty, 1945/2006b, p. 86). Por isso o escrevemos em maiúsculas, para marcá-lo como conceito transcendental, no sentido em que é condição da experiência de mundo e do que sentimos empiricamente nele. Ou seja, só podemos sentir isso ou aquilo porque um Sentir geral faz parte da abertura de qualquer experiência de mundo.

2 "O gesto linguístico, como todos os outros, desenha ele mesmo o seu sentido. Primeiramente essa ideia surpreende, mas somos obrigados a chegar a ela se queremos compreender a origem da linguagem, problema sempre urgente embora psicólogos e linguistas concordem em recusá-lo em nome do saber positivo." (Merleau-Ponty, 1945/2006b p. 253).

3 "Quer os estímulos desencadeiem, segundo as leis da mecânica nervosa, as excitações capazes de provocar a articulação da palavra, quer os estados de consciência acarretem, em virtude das associações adquiridas, a aparição da imagem verbal conveniente, nos dois casos a fala tem lugar em um circuito de fenômenos em terceira pessoa, não há ninguém que fale, há um fluxo de palavras que se produzem sem qualquer intenção de falar que as governe." (Merleau-Ponty, 1945/2006b, p. 238).
} 
como em outros momentos de sua obra, Merleau-Ponty revela uma relação antes de complementariedade do que de mútua negação entre os supostos adversários. Ambas abstraem o fenômeno expressivo a partir do mesmo movimento: pressupor uma distinção radical e uma relação necessária de exterioridade entre significado e significante.

Para as psicologias empiristas, a linguagem só pode ser compreendida como uma associação entre fatos (físicos, fisiológicos e psíquicos), que se dá segundo determinadas leis de funcionamento, as quais caberia ao cientista investigar. A sonoridade ou a forma escrita de uma palavra, dada no âmbito físico e decomposta em "estímulos”, seria recebida por um indivíduo e, através de uma série de associações, que em última instância se dão no plano da fisiologia, gerariam o fato psíquico do entendimento. $\mathrm{O}$ fenômeno expressivo se apresenta aqui de maneira oblíqua, pois a própria atividade de expressão se dispõe na forma de leis postas "em terceira pessoa”, sejam estas as leis da fisiologia nervosa ou mesmo leis de associação de estímulos.

Já a leitura intelectualista encontra nas palavras o meio através do qual o pensamento é veiculado. Trata-se então de reconhecer o fenômeno da significação, porém a partir de uma perspectiva que abstrai o fenômeno expressivo, ao denotar a materialidade da palavra (significante) como o mero invólucro sensível de um sentido supostamente imaterial e atemporal (significado). Entre o pensamento puro e os objetos reais, encontra-se a palavra, veículo de um significado que seria da ordem do primeiro, ou seja, da pura representação. Trata-se aqui, segundo o autor, de uma duplicação do conceito em uma operação categorial, que não supera os problemas da leitura empirista ao delegá-los ao plano do puro pensamento.

Ou seja, como efeito da distinção entre significado e significante, ambas as tradições compartilham da mesma limitação em compreender a expressão em seu sentido próprio. Não há como se reconhecer, sob a óptica objetivista, uma legítima unidade do signo, uma vez que não há a possibilidade de uma passagem interna do significante (puro invólucro sensível) ao significado (puro pensamento imaterial). Essa impossibilidade tem suas raízes na própria impossibilidade do objetivismo em dar conta da passagem do campo do sensível ao campo dos sentidos. A atividade expressiva encontra-se por um lado resumida a uma consequência de um processo fisiológico ou associativo plenamente determinado do começo ao fim, constituindo mais efeito ou impressão de sentido do que propriamente potência expressiva realizada. Tomada pelo outro extremo, a atividade expressiva apenas veicula um pensamento que a antecede, reclamando para um âmbito da pura representação a verdadeira atividade produtora de sentidos. Sintetiza o autor:

No que concerne à própria fala, o intelectualismo mal difere do empirismo e não pode, tanto quanto este, dispensar-se de uma explicação pelo automatismo. Uma vez feita a operação categorial, resta explicar a aparição da palavra que a conclui, e é mais uma vez por um meca- nismo fisiológico ou psíquico que se fará isso, já que a palavra é um invólucro inerte. Portanto, ultrapassa-se tanto o intelectualismo quanto o empirismo pela simples observação de que a palavra tem um sentido (Merleau-Ponty, $1945 / 2006$ b p. 241 , grifo original do autor).

É a partir deste reconhecimento que o autor dá destaque ao sentido gestual da fala, que neste momento de sua obra é o que funda toda atividade linguística. $\mathrm{O}$ gesto aparece aqui como o movimento no qual se observa o potencial expressivo do corpo próprio em ação. Trata-se para o autor de reconhecer a indissociabilidade entre significado e significante, na medida em que uma fenomenologia do ato expressivo revela que o primeiro habita o segundo:

O elo entre a palavra e seu sentido vivo não é um elo exterior de associação; o sentido habita a palavra, e a linguagem não é um acompanhamento exterior dos processos intelectuais. Somos conduzidos então a reconhecer (...) uma significação gestual ou existencial da fala. (Merleau-Ponty, 1945/2006b p. 262).

Ao relacionar o sentido do gesto ao âmbito existencial, o autor se distancia de uma concepção idealista do sentido da fala, definindo assim o gesto expressivo como parte do movimento mais geral da existência, o da relação entre subjetividade corporificada e mundo. A linguagem aqui definitivamente não aparece como atividade de veiculação de pensamentos, mas sim como termo integrante de uma tomada mais ampla de posição do sujeito em relação ao mundo: através da fala o sujeito intenciona o mundo de maneira significativa.

Como parte de sua argumentação descritiva, Merleau-Ponty (1945/2006b) aponta para certos aspectos do uso da linguagem e sua relação com o que na atitude natural seria o "puro pensamento", evidenciando certas incongruências que uma compreensão que coloca estes dois termos em relação de externalidade acaba por enfrentar. $\mathrm{O}$ argumento central evoca a experiência na qual observa-se que um pensamento adquire clareza de sentido no momento em que é enunciado ou expresso em linguagem:

Se a fala pressupusesse o pensamento, se falar fosse em primeiro lugar unir-se ao objeto por uma intenção de conhecimento ou por uma representação, não se compreenderia por que o pensamento tende para a expressão como para seu acabamento, por que o objeto mais familiar parece-nos indeterminado enquanto não encontramos seu nome, por que o próprio sujeito pensante está em um tipo de ignorância de seus pensamentos enquanto não os formulou para si ou mesmo disse e escreveu, como mostra o exemplo de tantos escritores que começam um livro sem saber exatamente o que nele colocarão. (Merleau-Ponty, 1945/2006b p. 241). 
A fala não surge na presente descrição, portanto, enquanto evocação ou tradução de um sentido já dado de antemão no âmbito de um puro pensamento. $\mathrm{O}$ fato de que o pensamento tende à expressão linguística para seu acabamento indica que a expressão é antes sua realização ${ }^{4}$ de fato do que a tradução de um suposto sentido dado em uma interioridade da consciência. Conforme argumenta o autor, para além de se constatar que o sentido se enraíza na fala, devemos levar em conta que a fala se caracteriza por ser a própria existência exterior do sentido. Trata-se de compreender a realização de um sentido como um fenômeno que ocorre no âmbito de uma espacialidade e na espessura de uma temporalidade. Restituir o sujeito falante, neste caso, não consiste em descrever um sujeito pensante por trás do ato expressivo, mas sim de identificar o sujeito como essa potência expressiva que articula um sentido que se realiza na espacialidade e na temporalidade da experiência e não é, portanto, a mera tradução ou invólucro sensível de um pensamento imaterial e atemporal:

As palavras só podem ser as "fortalezas do pensamento" e o pensamento só pode procurar a expressão se as falas são por si mesmas um texto compreensível e se a fala possui uma potência de significação que lhe seja própria. É preciso que, de uma maneira ou de outra, a palavra e a fala deixem de ser uma maneira de designar o objeto ou o pensamento para se tornarem a presença desse pensamento no mundo sensível e, não sua vestimenta, mas seu emblema ou seu corpo. (Merleau-Ponty, 1945/2006b p. 247).

Assim, o que o autor propõe neste momento é tomar o signo linguístico como inscrição efetiva de um significado no âmbito do sensível. Trata-se de equiparar a palavra falada a um gesto significativo dentre outros gestos possíveis. Porém, trata-se ainda de um tipo de gesto privilegiado, na medida em que revela de forma mais explícita aquilo que, ao longo dessa investigação acerca da percepção, a análise da motricidade revelou a respeito da espacialidade e o hábito em geral a respeito da unidade do corpo próprio.

Melhor ainda do que nossas observações sobre a espacialidade e a unidade corporais, a análise da fala e da expressão nos faz reconhecer a natureza enigmática do corpo próprio. Ele não é uma reunião de partículas das quais cada uma permaneceria em si, ou ainda um entrelaçamento de processos definidos de uma vez por todas - ele não está ali onde está, ele não é aquilo que é - já que o vemos secretar por si mesmo um "sentido" que não lhe vem de parte alguma, projetá-lo em sua circunvizinhança material e comunicá-lo aos outros sujeitos encarnados. (Merleau-Ponty, 1945/2006b p. 267).

4 "Assim a fala não traduz, naquele que fala, um pensamento já feito, mas o consuma." (Merleau-Ponty, 1945/2006b, p. 242).
A fala não remete a um poder de significar que advém "de fora”, mas sim de uma expressão que é realizada pelo próprio gesto. Tomado enquanto tal, é possível descrever o que ele nos revela a respeito da profunda relação entre corpo e mundo, no que tange à unidade do corpo enquanto potência de articular sentidos. Observa-se uma relação de continuidade entre os hábitos corporais, as formas de intencionar o mundo e as coisas em sua generalidade, e a potência expressiva observável deste corpo, quando considerado enquanto um polo possível da experiência sensível (ao ser observado por outrem ou se engajar em uma conversa com um interlocutor, por exemplo).

Sempre observaram que o gesto ou a fala transfiguravam o corpo, mas contentavam-se em dizer que eles desenvolviam ou manifestavam uma outra potência, pensamento ou alma. Não se via que, para poder exprimi-lo, em última análise o corpo precisa tornar-se o pensamento ou a intenção que ele nos significa. (Merleau-Ponty, 1945/2006b p. 267).

Ou seja, conforme completa Merleau-Ponty (1945/2006b, p. 267), é o corpo "que mostra, [é] ele que fala”, revelando na descrição da atividade perceptiva esse falar gesticulante que é mais próximo da ordem do produzir e do mostrar de fato um sentido imanente do que de simplesmente comunicar ou traduzir um pensamento possuído previamente. $\mathrm{O}$ desafio específico que a gesticulação verbal impõe é justamente o fato de a linguagem se apagar enquanto forma realizadora do pensamento, aparentando ser um mero veículo que, em última instância, conforme coloca Merleau-Ponty (1945/2006b p. 253), "visa uma paisagem mental que em primeiro lugar não está dada a todos e que ela tem por função justamente comunicar". Mas, conforme continua o filósofo, trata-se de um engano supor a necessidade de postulação desta zona de sentidos por definição inacessível. Há um caráter de comunalidade na linguagem que, se por um lado pode servir de subsídio para postulá-la como sistema autônomo, porque convencionalmente constituído, por outro pode ser ocasião de indicar um mundo comum ao qual a fala se refere, e assim poderia se dizer, com certo uso livre dos termos da parte de Merleau-Ponty (1945/2006b p. 253), que "o que a natureza não dá a cultura o fornece”.

Ao abordar o campo dos fenômenos linguísticos, é a unidade do corpo que apreende e se apropria das palavras enquanto objetos de $\mathrm{uso}^{5}$. A expressão linguística surge como parte dessa atividade geral do corpo, e dessa forma será inserida no campo do Sentir a partir da compreensão fenomenológica do corpo próprio. Os gestos ligados ao exercício da linguagem, em seus âmbitos mais diversos (fala, escrita, leitura, escuta) encontram-se em continuidade intrínseca com a atividade perceptiva geral do corpo - o que irá embasar neste

5 "Quanto ao sentido da palavra, eu o aprendo assim como aprendo o uso de um utensílio, vendo-o empregado no contexto de uma certa situação." (Merleau-Ponty, 1945/2006b, p. 540). 
momento o destaque dado ao sentido gestual da fala como primordial para a compreensão da linguagem. Há uma continuidade inexorável entre a abertura perceptiva e a ação expressiva, que se dá no âmbito da sensibilidade:

Em suma, meu corpo não é apenas um objeto entre todos os outros objetos, um complexo de qualidades entre outros, ele é um objeto sensível a todos os outros, que ressoa para todos os sons, vibra para todas as cores, e que fornece às palavras a sua significação primordial através da maneira pela qual as acolhe. (Merleau-Ponty, 1945/2006b, p. 317, grifo original do autor).

O uso da palavra configura, assim, uma relação possível com o mundo: uma vez que representa uma forma própria de relação de intencionalidade, de abertura do campo perceptivo, trata-se de um fenômeno estruturado nos limites da experiência perceptiva fundante mais ampla. O significado configura-se como uma parte do campo sensível. Para compreendermos melhor este aspecto, precisamos delinear de forma precisa o que o autor entende quando faz menção a este "acolhimento" da palavra, bem como a relação entre o corpo próprio e a possibilidade de uma "significação primordial" por ele fornecida às palavras. Trata-se de compreender o estatuto do fenômeno expressivo fundado na experiência perceptiva, que representará mudanças importantes em relação à conceituação inicial do autor acerca do comportamento simbólico.

\section{Gestualidade e o ingresso no mundo da linguagem}

É necessário precisar melhor essa "potência de significação" que o autor concede aqui às palavras, e sua relação com a unidade do corpo próprio, nível de análise no qual sua descrição se situa. Ao tratar da síntese do corpo próprio, Merleau-Ponty (1945/2006b) compara a unidade expressiva do corpo àquela da obra de arte, e a partir de tal comparativo oferece um vislumbre de uma noção de individualidade por trás do ato expressivo:

Um romance, um poema, um quadro, uma peça musical, são indivíduos, quer dizer, seres em que não se pode distinguir a expressão do expresso, cujo sentido só é acessível por um contato direto, e que irradiam sua significação sem abandonar seu lugar temporal e espacial. É nesse sentido que nosso corpo é comparável à obra de arte. Ele é um nó de significações vivas e não a lei de um certo número de termos co-variantes. (Merleau-Ponty, 1945/2006b p. 209-210).

Se compreendermos a fala como protensão natural dessa unidade primordial na qual, sem renunciar ao caráter de experiência situada na espessura de uma espacialidade e de uma temporalidade, podemos observar uma indistinção de fato entre o sentido expresso e o ato da expressão, fica claro que a indissociabilidade entre significado e significante é uma decorrência direta do movimento que busca fundar o fenômeno linguístico no sentido gestual.

Assim como a fala significa não apenas pelas palavras, mas ainda pelo sotaque, pelo tom, pelos gestos e pela fisionomia, e assim como esse suplemento de sentido revela não mais os pensamentos daquele que fala, mas a fonte de seus pensamentos e sua maneira de ser fundamental, da mesma maneira a poesia, se por acidente é narrativa e significante, essencialmente é uma modulação da existência. (Merleau-Ponty, 1945/2006b p. 209).

A palavra, enquanto uma modalidade de gesto, possui um sentido na medida em que remete a um estilo de interação com o mundo, a uma inflexão significativa da experiência, caracterizando uma verdadeira "modulação da existência". O paralelo entre o corpo próprio e a obra de arte nos auxilia a compreender essa relação de continuidade entre o corpo enquanto potência expressiva geral e os atos de significação enquanto gestos que modulam essa experiência geral de forma significativa no âmbito da experiência vivida. Podemos imaginar, a partir do paralelo entre o corpo e a obra de arte, que se a experiência do corpo se reveste de um caráter narrativo e significante, em certo nível trata-se também de um caráter espontâneo que se apresenta de forma liminarmente "acidental", tal é o traço imanente da expressividade considerando-se a vida da consciência a partir da experiência do corpo. Assim, a potência expressiva da palavra, compreendida a partir da noção de gesto, não se baseia mais em uma presumida generalidade do conceito apreendido em ideia, mas antes na generalidade vivida da experiência sensível. A palavra como realização de um sentido possui um caráter existencial:

A palavra "granizo", quando eu a conheço, não é um objeto que eu reconheça por uma síntese de identificação, ela é um certo uso de meu aparelho de fonação, uma certa modulação de meu corpo enquanto ser no mundo, sua generalidade não é a generalidade da ideia, mas a de um certo estilo de conduta que meu corpo “compreende" enquanto ele é uma potência de fabricar comportamentos e em particular fonemas. (Merleau-Ponty, 1945/2006b, p. 540).

Vemos aqui a continuidade entre a potência geral do corpo de "fabricar comportamentos" e a possibilidade que ela funda de recortar significativamente a experiência perceptiva a partir de gestos, com destaque especial para a vocalização de fonemas. Ao abordar a origem dos sentidos no nível do gesto, Merleau-Ponty procura desvelar os fenômenos de significação e produção de sentidos em estado nascente, retraçando a origem de toda expressão à mesma experiência pré-reflexiva comum de mundo. Desta feita, encontra-se desmistificado o poder de um suposto pensamento puro que abordaria em 
transparência a experiência empírica, que seria em si desprovida de um campo de sentido propriamente dito, a partir de uma relação de simples externalidade - aquela do entendimento ${ }^{6}$. O acoplamento entre a montagem pré-reflexiva da intencionalidade geral do corpo e o campo da linguagem se dará assim não na ordem do "eu penso", mas sim na ordem do "eu posso".

Esse desenvolvimento remonta às investigações de "A Estrutura do Comportamento" nas quais tratava-se de, a partir do conceito de estrutura e de forma, apontar para unidades de sentido presentes já na organização sensível do mundo e nas atividades vitais dos organismos. A noção de estrutura serviu de base ao autor para se pensar o problema da interioridade sem recair na necessária separação entre puro pensamento (ou pura interioridade que se retira do mundo) e puro factual (ou pura exterioridade que, sendo por definição plena, não comporta abertura possível à expressão e criação por parte do sujeito). Merleau-Ponty (1942/2006a) apresenta assim o fenômeno da forma ou Gestalt como uma unidade de sentido observável, o comportamento tendo um sentido que se desenha para aquele que o observa de maneira que não é nem por um lado posto pela consciência daquele que se comporta, nem apreendido enquanto representação pela consciência daquele que o observa.

O gesto, enquanto comportamento expressivo, efetua sua síntese de sentido no próprio comportar-se, ou seja, seu sentido se dá como configuração do mundo sensível e, se admitimos que ele tende para além da atualidade da situação, vemos que não se trata da postulação de uma interioridade absoluta na medida em que Merleau-Ponty (1945/2006b, p. 267) define sua potência de fazer "voltar a cair no ser aquilo que tendia para além", ou seja, de inserir o fenômeno da significação na (até então aparente) plenitude do sensível. Uma das maneiras de se compreender essa inscrição do cultural no sensível é abordando-a a partir do ponto de vista ontogenético ou da experiência individual. Neste sentido, as análises a respeito da percepção na infância podem se apresentar como promissoras:

A percepção de outrem e o mundo intersubjetivo só representam problema para os adultos. A criança vive em um mundo que ela acredita imediatamente acessível a todos aqueles que a circundam, ela não tem nenhuma consciência de si mesma, nem tampouco dos outros, como subjetividades privadas, ela não suspeita que nós todos e ela mesma estejamos limitados a um certo ponto de vista sobre o mundo. É por isso que ela não submete à crítica nem seus pensamentos, nos quais crê na medida em que eles se apresentam e sem procurar ligá-los, nem nossas falas. (Merleau-Ponty, 1945/2006b p. 475).

6 "A palavra nunca foi inspecionada, analisada, conhecida, constituída, mas apanhada e assumida por uma potência falante e, em última análise, por uma potência motora que me foi dada com a primeira experiência de meu corpo e de seus campos perceptivos e práticos." (Merleau-Ponty, $1945 / 2006$ b, p. 540).
O que está em jogo aqui é compreender que a infância revela um modo de ser e de se relacionar com o mundo (natural e humano, sem distinção) que não é aquele da consciência reflexiva que intenciona um objeto. Mais do que postular a existência ou as formas com que se dão as vivências sincréticas na infância, nosso interesse aqui é chamar atenção para essa camada da experiência subjetiva que, a partir da descrição da experiência do corpo próprio na fase adulta, se revela como nunca completamente superada ${ }^{7}$.

A experiência da criança constitui a vivência empírica de formas de relação pré-reflexivas com o outro e com o mundo. Cronologicamente primeira, é nela que se fundam as bases através das quais o sujeito se reporta ao mundo, sendo que prova disso é justamente reconhecer que tais formas não são jamais completamente superadas na experiência adulta. Na verdade, torna-se necessário reconhecer que a experiência adulta só existe sucedendo e se apoiando sobre esse modo de ser infantil, mas nunca o suplantando por completo, como se a percepção adulta se definisse como um deixar absolutamente de se abrir ao mundo a partir de tais formas “incipientes". Assim, o valor da descrição da experiência infantil é o de que ela se apresenta como uma redução fenomenológica espontânea, como que um retorno a uma camada pré-reflexiva que é dada de fato na experiência e não simplesmente construída através do discurso filosófico.

A percepção incipiente nos sugere a emergência de significações humanas que são por direito inseparáveis do conteúdo sensível em que elas se encarnam: o que a criança apreende anteriormente à percepção de um material sonoro e da intelecção de um sentido puro é uma entonação, um estilo, que precede a distinção entre a expressão e o exprimido. (Bimbenet, 2004 p. 163, tradução nossa)

Ou seja, na percepção incipiente observa-se de forma marcada aquilo que muitas análises a respeito dos fenômenos linguísticos deixam de levar em conta, justamente por pressupor uma consciência adulta definida pelo cogito e, portanto, na qual o pensamento e a intelecção precedem a expressão e com ela se relacionam sob uma intransponível disposição em exterioridade, fazendo com que a última acabe por se caracterizar como um momento secundário de tradução de um sentido sempre ulterior. Nota-se assim uma confluência entre a descrição da potencialidade expressiva do corpo como fundada no nível da fala e as análises a respeito da percepção incipiente: ambas revelam esse nível de apreensão no qual não há distinção de fato entre um material sonoro vazio de sentido e um sentido puro exterior ao campo fenomênico. Expressão e

$7 \quad$ Noção presente na crítica que Merleau-Ponty (1945/2006b p. 475) dirige às teorias do desenvolvimento de Piaget: "Piaget conduz a criança até a idade da razão como se os pensamentos do adulto se bastassem e suprimissem todas as contradições. Mas, na realidade, é preciso que de alguma maneira as crianças tenham razão contra os adultos ou contra Piaget, e que os pensamentos bárbaros da primeira idade permaneçam sob os pensamentos da idade adulta como um saber adquirido indispensável, se é que deve haver para o adulto um mundo único e intersubjetivo." 
exprimido encontram-se em uma relação de fundação mútua, uma vez tomados enquanto um polo significativo de um posicionamento no mundo que não é outro senão aquele do esquema corporal.

Assim, vimos como as análises de Merleau-Ponty a respeito da percepção incipiente, ao abordar a relação da criança com o mundo humano e seu ingresso no mundo cultural através da aquisição da linguagem nos permitem evidenciar alguns aspectos da forma como a imbricação entre natureza e cultura se dá na experiência individual. Trata-se de um momento de especial importância para compreendermos um pouco melhor a continuidade possível entre a arqueologia do natural e a teleologia da expressão que passamos a observar ao nos voltarmos para a investigação dos poderes expressivos do corpo próprio. O "pacto natural" entre corpo e mundo, o qual a descrição da experiência perceptiva revela, abre a possibilidade de que o gesto corporal sustente um sentido material como que irradiado pelo próprio movimento que define. Assim é que, como vimos, a percepção incipiente se mostra capaz de intentar as coisas "pela encarnação daquilo que exprimem, porque nelas sua significação humana se aniquila e se oferece, literalmente, como aquilo que elas querem dizer". (Merleau-Ponty, 1942/2006a p. 390)

\section{O campo de sentidos comum}

Posteriormente, Merleau-Ponty (19491952/2006c) utiliza-se dos trabalhos de Guillaume a respeito da imitação para precisar certos aspectos dessa temática. O autor aponta como grande contribuição de tais análises o reconhecimento de que todo gesto, uma vez que sempre se dá no mundo e cujo efeito de sentido se dá enquanto polarização em direção a um objetivo localizado num plano comum de experiência, não é acessível para criança enquanto representação interna da consciência que outrem teria do próprio gesto, mas sim através da mediação do próprio mundo, enquanto polo comum para o qual se orienta a ação de ambos.

A interpretação clássica da imitação supõe uma análise por mim das condições motrizes dos gestos de outrem e baseia-se numa identificação prévia de suas atitudes e das minhas. Guillaume propõe inverter o problema: o que, para os psicólogos clássicos, é condição prévia, para ele não passa de consequência: em vez de dizer que a identificação do corpo de outrem e do meu, através dos aspectos cinestésico e visual, produz a imitação, Guillaume diz que a criança imita primeiro o resultado da ação com seus próprios meios e consegue assim produzir os mesmos movimentos do modelo. O terceiro termo entre mim e outrem será o mundo exterior, os objetos aos quais se dirigem a ação alheia e a minha. (Merleau-Ponty, 1949-1952/2006c p. 25)

A imitação mediada pelo objetivo diz respeito ao intencionar, tomando o corpo próprio não enquanto uma representação clara do próprio movimento, mas antes como esse meio sistemático de intencionar os objetos, o mesmo objetivo que se observa atingido pela conduta de outrem. Diz respeito, assim, mais ao resultado global que aos detalhes topológicos do gesto, mais ao efeito da ação do que à precisão proprioceptiva. No caso específico da linguagem, trata-se da articulação entre a fala do outro - com seu efeito de sentido compreendido em um âmbito prático - e a própria fala, a qual a criança tem acesso a partir da própria audição.

Os detalhes do gesto são secundários à intenção expressiva que se modula de maneira imediata. Desta forma, percebe-se que o ingresso no mundo da linguagem consiste na aquisição contínua e sucessiva de hábitos expressivos, os quais giram sempre em torno de ações dotadas de sentido, prescindindo assim a necessidade de se postular, neste nível prático e primário de experiência, uma ligação conceitual entre uma ideia e sua tradução fonética. Pois aqui não se trata de ideia, mas antes de um efeito de sentido evidente inicialmente no mundo, e a articulação fonética age justamente no sentido de recortar essa experiência de mundo a partir dos meios de expressão oferecidos em determinada formação linguística.

Desta forma, o problema é recolocado ${ }^{8}$, e uma investigação a respeito do sistema sedimentado da língua se anuncia, sem que com isso se perca a dimensão da expressividade que as descrições a respeito da fala no corpo próprio faziam aparecer. Significante e significado constituem-se mutuamente, na aquisição da linguagem pela criança, através de uma atividade intencional comum. Retomando o exemplo da palavra "granizo", em "Fenomenologia da Percepção", vemos que o autor apresenta essa dimensão do aprendizado por imitação de forma semelhante:

Um dia eu "apanhei" a palavra granizo assim como se imita um gesto, quer dizer, não decompondo-a e fazendo corresponder a cada parte da palavra ouvida um movimento de articulação e de fonação, mas escutando-a como modulação única do mundo sonoro, e porque esta entidade sonora se apresentava como "algo a pronunciar" em virtude da correspondência global que existe entre minhas possibilidades perceptivas e minhas possibilidades motoras, elementos de minha existência indivisa e aberta. (Merleau-Ponty, 1945/2006b p. 540).

O componente imitativo, longe de sinalizar uma exterioridade entre uma ideia pura e sua expressão fonética cuja forma pronta é estabelecida por convenção, aponta para um sentido que se dá enquanto uma modulação da potência expressiva geral do corpo, que se constitui na própria atividade de expressão, na gesticulação da palavra. A unidade sonora se apresenta como esta unidade capaz de polarizar a percepção do ouvinte de modo que ela não o reconheça simplesmente como objeto externo, mas reencontre através dela, a cada momento, a "correspondência global" entre as suas potências perceptiva e motora. A comunicação se dá em um

8 "O problema não é descobrir como significações se agregam de fora aos signos, mas sim como os fonemas se articulam mutuamente, como o som recorta o mundo do sentido. O conjunto dos signos fônicos mostra as gesticulações, os movimentos no mundo do significado." (Merleau-Ponty, $1949-1952 / 2006$ c p. 21). 
nível gestual que não necessita lançar a premissa de uma partilha de sentidos intelectuais comuns entre os sujeitos expressivos, já que o sentido se dá na própria tessitura comum da experiência.

Engajo-me com meu corpo entre as coisas, elas coexistem comigo enquanto sujeito encarnado, e essa vida nas coisas não tem nada de comum com a construção de objetos científicos. Da mesma maneira, não compreendo os gestos do outro por um ato de interpretação intelectual, a comunicação entre as consciências não está fundada no sentido comum de suas experiências, mesmo porque ela o funda: é preciso reconhecer como irredutível o movimento pelo qual me empresto ao espetáculo, me junto a ele em um tipo de reconhecimento cego que precede a definição e a elaboração intelectual do sentido. (Merleau-Ponty, 1945/2006b p. 252)

De forma que a fala se caracteriza como um “espetáculo” cujo sentido não é indiferente à capacidade de vocalização daquele que a escuta. A palavra, sendo um "algo a pronunciar", solicita do corpo a vocalização assim como os objetos de uso solicitam, na percepção infantil, a intencionalidade implícita envolvida em sua criação e funcionamento. O fenômeno da imitação nos revela este "reconhecimento cego" do sentido gestual, que só é compreendido a partir do termo comum do mundo sensível, que neste momento da obra do autor é o que funda uma conaturalidade das consciências. Por isso a aquisição da linguagem por meio da imitação só pode ser realmente compreendida a partir da inserção deste terceiro termo.

Vimos que, na experiência da criança, conforme descrita inicialmente por Merleau-Ponty, o mundo cultural precede o mundo natural, a criança se vê primariamente inserida em um mundo que já apresenta a todo momento as marcas indeléveis da transformação humana - seja na organização dos espaços urbanos, seja na observação e apropriação dos objetos de uso, por exemplo. Cabe ressaltar aqui, sob o benefício retrospectivo das análises sobre a fala, que se trata também de um mundo eminentemente falado. Se o mundo cultural deve configurar de alguma forma uma retomada concreta do mundo natural, destaca-se o fato de que o acesso da criança aos sentidos culturais é mediado eminentemente pela fala. O caráter da forma ou estrutura de estabelecer uma continuidade entre natureza e consciência remete às análises de "A Estrutura do Comportamento", sendo que agora retomamos o assunto no contexto da recolocação radical da questão da consciência conforme efetuada pela "Fenomenologia da Percepção".

Encontramos assim, do lado da percepção infantil, a mesma totalização do sensível já encontrada na ordem vital. O conceito de forma, que presidiu a apreensão dos comportamentos animais, é naturalmente estendido nesse a priori material, se é verdade que nos dois casos nós lidamos com as significações imanentes ao seu desdobramento sensível. (Bimbenet, 2004 p. 163)
É justamente porque comportamento e percepção se dão sempre a partir de estruturas, são duas faces de um mesmo engajamento concreto e estrutural com o mundo, que a expressividade humana se torna passível de ser compreendida como expressão concreta, desdobramento de um sentido antes inscrito no âmbito do Sentir do que pensado no âmbito das puras idealidades. A fala não apenas realiza um sentido sensível no momento em que é enunciada, mas, como demonstrarão os estudos posteriores do autor a respeito do poder expressivo dos sistemas linguísticos, na medida em que se sedimenta enquanto linguagem, enquanto abre a possibilidade de uma interlocução e de uma historicidade das falas, enforma um campo inerente de expressividade a toda ação humana. Neste sentido é que o filósofo afirma que "o ato de expressão constitui um mundo linguístico e um mundo cultural”, sendo que é deste poder articulador originário que provém sua capacidade de fazer "voltar a cair no ser aquilo que tendia para além”. (Merleau-Ponty, 1945/2006b p. 266)

A fala, pelo caráter de sedimentação de sentidos e pelo seu papel na própria modulação da experiência vivida, se destaca dentre a variedade de comportamentos e gestos possíveis da criança. Porém, ela não deixa nunca de se apresentar enquanto um prolongamento indissolúvel da atividade corpórea total. Assim, cabe compreender que a aquisição da linguagem não equivale ao aprendizado de um determinado sistema complexo de formas que serviria ao propósito de traduzir um pensamento já potencialmente existente de forma autônoma na criança - se, afinal de contas, o pensamento se pensa na fala, ele se pensa através da língua. As formas oferecidas pela língua não são vazias de sentido, não podem configurar um sistema de invólucros inócuos, o que seria um erro passível de se cair caso se ressalte em excesso o caráter convencional da língua, em detrimento de seu caráter eminentemente expressivo e significativo. Além disso, mesmo que se reconheça a importância da unidade indissociável entre significado e significante, no terreno da reabilitação conceitual proposta por Merleau-Ponty não será suficiente admitir um significante que simplesmente realize a síntese sensível de um significado posto à luz por uma suposta consciência constituinte. $\mathrm{O}$ gesto não corresponde de fora a um estado de consciência dado, é antes o avesso de uma "maneira de acolher a situação e vivê-la”, conforme vimos. Justamente por se enraizar na "variação de nosso ser no mundo", a expressividade encontra-se destarte em interpenetração com a abertura afetiva ao mundo, parte de uma subjetividade cujo ser sempre se dispõe como um projeto ativo de mundo (Marcon \& Furlan, 2015).

\section{Intergestualidade e as estruturas do sistema linguístico}

O mesmo movimento conceitual que nos garante a impossibilidade de um signo inteiramente natural coloca em xeque a noção de um signo artificial, de maneira que o que está questionado 
aqui, entrevisto através da negação desta distinção entre o natural e o fabricado, é justamente o estatuto desta “fabricação”, que em última instância nos leva a uma experiência do "natural” que já é sempre culturalizada, sempre perpassada pelos modos de ser da cultura, como a análise da percepção infantil nos mostrou. É com base nesta leitura da aproximação entre os signos naturais e culturais que Merleau-Ponty sinaliza a possibilidade de uma origem comum aos signos linguísticos, dirigindo-se assim ao enfrentamento da complexa questão da convencionalidade e arbitrariedade dos significantes. Para compreender de que maneira determinada articulação fonética desenha um gesto culturalmente investido de sentido, seria necessário traçar suas origens para aquém das convenções do uso linguístico, assumidas como dadas em determinado momento de seu uso.

Se pudéssemos retirar de um vocabulário aquilo que é devido às leis mecânicas da fonética, às contaminações das línguas estrangeiras, à racionalização dos gramáticos, à imitação da língua por si mesma, descobriríamos sem dúvida, na origem de cada língua, um sistema de expressão muito reduzido, mas tal, por exemplo, que não seria arbitrário chamar de luz a luz se chamamos de noite a noite. (Merleau-Ponty, 1945/2006b p. 254-255).

Tal concepção de um sistema original de signos, no qual a própria sonoridade das palavras encontrar-se-ia em direta continuidade com o percebido, foi em grande parte abandonada posteriormente pelo autor, principalmente a partir dos estudos que efetua a respeito da linguística de Saussure. Conforme afirma Bimbenet (2004), Merleau-Ponty efetuará uma leitura própria da linguística de Saussure, que precede a apropriação que posteriormente o trabalho do linguista teria nas chamadas correntes estruturalistas, para as quais seus escritos teriam importância central na construção de uma compreensão própria do sentido da cultura e da história.

Será na conceptualização do sentido diacrítico do signo, um dos pontos centrais da linguística saussuriana, que Merleau-Ponty encontrará a resposta para encaminhar uma solução para a antinomia decorrente da arbitrariedade do signo linguístico. Trata-se do conceito de que o sistema linguístico funciona em uma dinâmica de valores na qual o sentido de cada signo é determinado por uma rede complexa de oposições entre os signos (relações significantes - significantes) e não pela justaposição arbitrária de um signo a determinado sentido isolado (relações significantes - significados), a qual é segunda em relação àquela mais originária.

Portanto, o signo linguístico não é para Saussure (1916/2012) o índice de um significado que existiria potencialmente enquanto qualidade pura e discreta na experiência. Como alternativa à ligação entre um significado puro e um significante arbitrário, o linguista enfatiza a ideia de valor significativo. Tomado no sentido forte do termo, o linguista afirma que o valor do signo deve ser compreendi- do no sentido rigorosamente de uma amplitude de grandeza, o que implica necessariamente a relação com outros semelhantes, já que toda valoração, tomada neste sentido, presume um horizonte valorativo no qual pode haver substituições ou trocas entre os termos valorados. Neste sentido, podemos pensar no sistema linguístico como um campo de signos historicamente sedimentados em constante relação com uma atividade expressiva que, ao mesmo tempo em que se apoia sobre este campo para se efetivar, molda-o de acordo com essa própria intenção expressiva.

O sentido diacrítico não aparecerá, portanto, apenas como um princípio ordenador da linguagem. Para além disso, nos auxiliará na explicitação da continuidade possível entre a experiência pré-linguística ou silenciosa do mundo e o mundo já falado através da linguagem. Mais especificamente, de que forma este "mundo do significado" se inscreve necessariamente em uma experiência sensível, de forma que, como vimos, a própria sonoridade da fala possa ter um papel estruturante na percepção. A diferenciação da sonoridade entre os fonemas, experimentada pela criança ao longo de seu progressivo ingresso na língua materna, já representa o momento embrionário da potência significativa da linguagem.

As oposições fonêmicas - contemporâneas das primeiras tentativas de comunicação - aparecem e desenvolvem-se sem relação alguma com o balbucio, amiúde reprimido por elas, que em todo caso não conserva a partir daí senão uma existência marginal e cujos materiais não são integrados ao novo sistema da palavra verdadeira, como se não fosse o mesmo possuir um som a título de elemento do balbucio, que se dirige apenas a si, e como momento de um empreendimento de comunicação. Pode-se dizer que a criança fala e depois aprenderá apenas a aplicar diversamente o princípio da palavra. A intuição de Saussure se precisa: com as primeiras oposições fonêmicas a criança inicia-se na ligação lateral do signo com o signo como fundamento de uma relação final do signo com o sentido - na forma especial que recebeu na língua em questão. (Merleau-Ponty, $1960 / 1991$ p. 40 , grifo original do autor).

Esta leitura já se utiliza do conceito de diacriticidade para compreender uma linguagem que desde seu início se dá como operação de diferenciação. O autor chama a atenção para o fato de que não devemos confundir a gesticulação desordenada do balbucio com o uso incipiente dos fonemas que compõem a língua materna, já que o segundo intenta um campo comunicativo, enquanto o primeiro representa um uso gratuito do aparelho fonético que não se direciona ao mesmo efeito. A aquisição da linguagem, como vimos, não é apresentada pelo autor como uma operação de entendimento ${ }^{9}$, na qual

9 O tema retorna em um curso de 1953, quando o autor aborda o "Problema da Fala". Com base na linguística do saussuriano Jakobson, Merleau-Ponty (1953-54/1968) retoma a "deflação súbita" da variedade de gesticulação sonora no momento do ingresso na fala, que é apontado por Jakobson como emblemático da inserção do infante no sistema de 
se adquiriria uma potência de codificação da experiência. Trata-se antes de uma inserção gradativa no campo significativo da linguagem, de modo que a fala situada precede a universalização do princípio sistemático que a sustenta. Além de nos convocar a compreender melhor esta relação entre a inserção no mundo da linguagem e a "posse" do sistema linguístico como princípio ordenador da expressão, trata-se também de pôr definitivamente em perspectiva o poder expressivo do gesto, que não pode ser pensado aqui distanciado do sistema linguístico no qual se apoia. Com isso, somos levados a reconhecer o componente organizador da linguagem que se apresenta, já na experiência de aprendizado da língua, como campo não apenas privilegiado, mas ainda necessário para um empreendimento de comunicação, na medida em que a linguagem se define como este campo de atividade significativa que possibilita que haja sentidos enquanto diferenciação e articulação gestual do mundo:

Se o signo só quer dizer algo na medida em que se destaca dos outros signos, seu sentido está totalmente envolvido na linguagem, a palavra intervém sempre sobre um fundo de palavra, nunca é senão uma dobra no imenso tecido da fala. Para compreendê-la, não temos de consultar algum léxico interior que nos proporcionasse, com relação às palavras ou às formas, puros pensamentos que estas recobririam: basta que nos deixemos envolver por sua vida, por seu movimento de diferenciação e de articulação, por sua gesticulação eloquente. (Merleau-Ponty, 1960/1991 p. 42-43)

Ou seja, se por um lado o sentido diacrítico relativiza o poder expressivo da gestualidade no âmbito da linguagem, no sentido em que faz com que ele necessariamente evoque seu sistema de valoração como horizonte necessário para que seja possível a própria expressão, vemos que a experiência efetiva do sistema linguístico se organiza de tal forma que a diferenciação é experimentada mais como campo eloquente de ação (gesticulação) do que como inserção assumida em um campo de valores dado. O horizonte de sentidos diacríticos da linguagem é, antes de tudo, indefinido.

Através do exercício da potência gestual da fala a criança se insere gradativamente em um sistema linguístico que, no entanto, não possui, já que ele atua como horizonte expressivo geral, conquanto sua relação com ele não é de entendimento ou conhecimento, mas remetida à uma camada mais originária da experiência. A totalidade da língua se apresenta a cada dobra expressiva, na medida em

oposições fonemáticas que integram o sistema linguístico no qual ele se insere. No entanto, Merleau-Ponty critica a posição jakobsoniana no que tange à interpretação de tais processos: "Quando ele está próximo de compreender como se dá a apropriação do sistema fonemático pelo infante, e como ao mesmo tempo a melodia da linguagem (...) se encontra por ela subitamente investida, R. Jakobson evoca a atenção e o juízo, em outras palavras, as funções de análise e objetivação que na realidade se apoiam sobre a linguagem e que, além disso, acabam por desconsiderar o aspecto atípico dos signos e das significações como o de sua indistinção para o infante.” (Merleau-Ponty, 1953-54/1968 p. 34-35, grifos originais do autor). que ingressar no mundo da linguagem passa a ser adquirir a capacidade de aplicar este "princípio da palavra”, ou seja, perceber e expressar o mundo através deste sistema de diferenciações que não necessariamente precisa ser percorrido por inteiro para que dela se faça uso.

Os fonemas constituintes da linguagem materna se destacam da miríade de possibilidades que o aparelho de fala garante, e o fazem justamente ao adquirirem uma potência organizadora que os outros fonemas possíveis não possuem: a capacidade de comunicação, de envolvimento e abertura para um campo compartilhado de ação. É na experiência de um mundo comum, na inserção da criança em um campo original de intergestualidade que o aprendizado da língua se torna possível. A língua materna envolve a experiência da criança e é através de suas formas próprias - e aqui nos referimos aos fonemas, às palavras, sentenças e até às formas sintáticas mais complexas - que ela passa a intentar o mundo, na medida em que sua atividade expressiva é tragada ${ }^{10}$ pelo sistema de valores sonoros que a circundam e se oferecem espontaneamente como a possibilidade de fazer ressoar em si essa potência significante que os outros projetam em torno de si.

Se os fonologistas conseguem estender a análise além das palavras, às formas, à sintaxe e até às diferenças estilísticas, é a língua inteira como estilo de expressão, como maneira única de utilizar-se da palavra, que é antecipada pela criança com as primeiras oposições fonêmicas. (...) Só a língua como um todo permite compreender como a linguagem atrai a criança para si e como esta consegue entrar nesse domínio cujas portas, era de acreditar, só se abrem do interior. É porque o signo é de imediato diacrítico, é porque se compõe e se organiza consigo mesmo, que ele tem um interior e acaba por reclamar um sentido. (Merleau-Ponty, 1960/1991 p. 41)

A dinâmica de valoração articula assim um campo diferencial gradativo, que vai desde a diferenciação entre os fonemas básicos que constituem a variação fonética da língua em questão, passando pela diferenciação entre as palavras e pela sintaxe, se estendendo até mesmo aos elementos mais sutis da organização do sistema, como a estilística. A crítica de Merleau-Ponty à leitura saussuriana é a de um distanciamento da articulação semântica em relação à articulação efetiva das coisas mesmas, no âmbito da experiência vivida. É preciso compreender de que forma a língua é capaz de articular sentidos diversos sob formas diversas que, no entanto, não apenas emergem de uma experiência de mundo comum como efetivamente possuem sobre ela um papel modulador. A imagem do turbilhão, evocada

10 "O todo da língua falada a tragaria como um turbilhão, a tentaria por suas articulações internas e a conduziria quase até o momento em que todo esse ruído significará algo. A incansável confirmação da cadeia verbal por si mesma, a emergência um dia irrecusável de uma certa gama fonêmica segundo a qual o discurso é visivelmente composto, forçariam afinal a criança a passar para o lado daqueles que falam." (Merleau-Ponty, 1961/1991 p. 40-41). 
por Merleau-Ponty, como vimos, tanto na descrição da percepção do comportamento significativo de outrem quanto ao tratar do ingresso no mundo da fala, remete a essa potência organizadora a qual se impõe sobre e é ao mesmo tempo assumida pelo sujeito falante, possuindo um caráter transformador sobre a própria experiência perceptiva.

Para o autor, tal modulação não deve ser compreendida como uma operação do entendimento ou do juízo, já que a linguagem se apresenta como condição mesma para o exercício de tais operações. É preciso compreender bem a passagem entre estas duas articulações, que se dão de forma indistinta na experiência pessoal (como o efeito de auto-esquecimento da linguagem bem nos atesta), mas cuja passagem não é unívoca, já que é possível "falar o mesmo mundo" de formas indefinidamente diversas - através dos diferentes sistemas linguísticos, em diferentes momentos históricos de um mesmo sistema linguístico e enfim nas variações estilísticas e nos múltiplos modos de expressão que coexistem dentro de um mesmo sistema linguístico tomado em qualquer ponto de sua história.

\section{Considerações finais}

No contexto da descrição da experiência perceptiva, o gesto nos aparece como uma unidade significativa que desenha o próprio sentido, sendo antes a realização efetiva de um sentido do que seu portador em externalidade. O gesto da fala, a vocalização da palavra, representa essa realização direta de um significado, e podemos compreendê-lo como uma protensão da unidade primordial do meio expressivo original que é o corpo. Contestar o dualismo cartesiano envolve pôr em xeque as garantias de uma consciência que possui os significados em sua forma pura e autônoma, exterior e anteriormente à experiência do mundo.

Se por um lado procuramos apresentar de que forma o autor efetua este termo de sua contestação, será preciso nos dirigirmos também, para além do sujeito falante, ao mundo do qual necessariamente se fala. Mundo enquanto campo primordial e geral da experiência que, como vimos, é o termo comum e ponto de apoio de toda possibilidade de comunicação. A consciência corporificada não intenciona nem puras idealidades, nem objetos cuja aparição fenomênica remontaria, em última instância, a categorias puras de entendimento. A análise da expressão e da fala cumprem o papel de demonstrar essa capacidade "enigmática"11" de transcendência que o corpo próprio possui. Complementando as análises a respeito da espacialidade e a unidade corporais, o gesto surgiu como possuindo um sentido existencial, que é aquele em que ao mesmo tempo que se enraíza em uma situação e em um mundo, possui esse mundo e essa situação como possibilidades sempre renovadas de ação significativa. Tra-

11 "É preciso reconhecer então essa potência aberta e indefinida de significar - quer dizer, ao mesmo tempo de apreender e de comunicar um sentido - como um fato último pelo qual o homem se transcende em direção a um comportamento novo, ou em direção ao outro, ou em direção ao seu próprio pensamento, através de seu corpo e de sua fala." (Merleau-Ponty, $1945 / 2006$ b p. 263). ta-se assim de uma reabilitação do aspecto existencial da expressão, que deixa de ser o mero veículo do puro pensamento para se caracterizar enquanto essa atividade encarnada que não é constituição de um sentido sobre um mundo pleno e exterior, mas antes vivência indissociada de um mundo de sentidos através da própria atividade expressiva, compartilhada intersubjetivamente em um horizonte cultural.

Essa abertura sempre recriada na plenitude do ser é o que condiciona a primeira fala da criança, assim como a fala do escritor, a construção da palavra, assim como a dos conceitos. É essa função que adivinhamos através da linguagem, que se reitera, apoia-se em si mesma ou que, assim como uma onda, ajunta-se e retoma-se para projetar-se para além de si mesma (Merleau-Ponty, 1945/2006b p. 267).

A subjetividade, portanto, enquanto dotada de um caráter eminentemente expressivo, encontra sua possibilidade de articulação de sentidos fundada no corpo, bem como em um horizonte intersubjetivo de meios de expressão compartilhados. A possibilidade de criação e originalidade remete aqui necessariamente a uma situação que a ultrapassa, mas que ao mesmo tempo é aquela sobre a qual toda criação necessariamente se apoia. Concomitante à reabilitação do sujeito perceptivo, a descrição fenomenológica da expressividade gestual da fala, na dinâmica de radical abertura ao mundo percebido (das "coisas" e da "experiência" de que falam as falas) se fazem cruciais para compreendermos a natureza de uma experiência linguística tomada em sua originalidade, para aquém da abstração dualista. Trata-se de recolocar a questão da consciência de modo que ela possa emergir internamente ao mundo que anteriormente se supunha apenas representar, e o que tratamos por significado, assim como o significante, passem a se referir unívoca e diretamente àquilo que são e intentam justamente por se apresentarem em sua espessura espaço-temporal, que é aquela da própria experiência de ser corpo. 


\section{Referências}

Bimbenet, É. (2004). Nature et humanité: le probleme anthropologique dans l'ouvre de Merleau-Ponty. Paris: Vrin.

Ferraz, M. S. A. (2009). Fenomenologia e ontologia em Merleau-Ponty. Campinas, SP: Papirus.

Furlan, R. (2012). Merleau-Ponty e Descartes: o afeto entre a medicina e a psicologia. Psicol. clin. 24(2), 101114

Marcon, G. H. \& Furlan, R. (2015). Afeto e subjetividade nos primeiros trabalhos de Merleau-Ponty. Memorandum, 29, 208-232.

Merleau-Ponty, M. (2006a). A Estrutura do Comportamento (M. V. M. Aguiar, trad.). São Paulo: Martins Fontes. (Obra original publicada em 1942).

Merleau-Ponty, M. (2006b). Fenomenologia da Percepção (C. A. R. Moura, trad.). São Paulo: Martins Fontes. (Obra original publicada em 1945).

Merleau-Ponty, M. (2006c). Psicologia e pedagogia da criança: curso da Sorbonne 1949-1952. (I. C. Benedetti, Trad.). São Paulo: Martins Fontes.

Merleau-Ponty, M. (1968). Résumés de cours - Collège de France, 1952-1960. Paris: Gallimard.

Merleau-Ponty, M. (1991) Signos (E. G. G. Pereira, trad.) São Paulo: Martins Fontes (Obra original publicada em 1960).

Moutinho, L. D. S. (2006). Razão e experiência: ensaios sobre Merleau-Ponty. Rio de Janeiro: Editora UNESP.

Verissimo, D. S., \& Furlan, R. (2006). Merleau-Ponty e a evolução espontânea da psicologia. Temas em Psicologia, 14(2), 143-151.

Verissimo, D. S., \& Furlan, R. (2007). Entre a Filosofia e a Ciência: Merleau-Ponty e a Psicologia. Paidéia (Ribeirão Preto), Ribeirão Preto, v. 17, n. 3.

Saussure (2012). Curso de Linguística Geral. (A. Chelini, J. P. Paes, I. Blikstein trad.) São Paulo: Cultrix (Obra original publicada em 1912).
Gilberto Hoffmann Marcon é Psicólogo, Mestre em Psicologia pela Universidade de São Paulo - USP, Faculdade de Filosofia, Ciências e Letras de Ribeirão Preto, Departamento de Psicologia. Ribeirão Preto - SP. E-mail: ghmarcon@gmail.com

Reinaldo Furlan é Professor Livre-Docente na Universidade de São Paulo - USP, Faculdade de Filosofia, Ciências e Letras de Ribeirão Preto, Departamento de Psicologia. Av. Bandeirantes, 3900, Monte Alegre, CEP 14040-901, Ribeirão Preto - SP. E-mail: reinaldof@ffclrp.usp.br

Recebido em 27.07.17

Primeira decisão editorial em 10.01.18

Aceito em 14.04.18 